\title{
INFLUÊNCIA DA COMPETIÇÃO COM TRAPOERABA NO CRESCIMENTO DO QUIABEIRO
}

\author{
Ualace de Oliveira dos Reis ${ }^{1}$ \\ Roberto Mauri Marques ${ }^{2}$ \\ Reinys Pogian Alves ${ }^{3}$ \\ Amanda Dutra de Vargas ${ }^{4}$ \\ Maria Laura Urbano Nascimento ${ }^{5}$ \\ Leandro Pin Dalvi ${ }^{6}$
}

Resumo: A cultura do quiabo é cultivada em todo o Brasil, devido a sua resistência e rentabilidade. Apesar disso, apresenta emergência de plântulas e crescimento primário lentos, além de ser cultivado em espaçamentos amplos, o que favorece o surgimento de plantas invasoras. Essas plantas são responsáveis por grandes perdas na produtividade, por possuírem um alto poder competitivo e pela produção de substâncias alelopáticas. Dentre as mais importantes encontra-se a trapoeraba (Commelina Spp.). 0 objetivo do trabalho foi avaliar a interferência competitiva da trapoeraba em diferentes densidades de infestação sobre a cultura do quiabo. As avaliações foram realizadas 50 dias após o transplante do quiabeiro. A comunidade infestante demonstrou uma influência negativa ao nível de duas e três plantas por vaso em todas as variáveis avaliadas, levando à conclusão de que altas densidades da mesma podem causar grandes prejuízos no cultivo. Em densidades menores, como ao nível de competição de uma planta por vaso, não houve influência negativa no crescimento inicial do quiabeiro.

Palavras-chave: Abelmoschus esculentus; Commelina difusa; Plantas Daninhas.

\footnotetext{
${ }^{1}$ Agronomia, Universidade Federal do Espírito Santo, Brasil. E-mail: ualaceoliveira@outlook.com.

${ }^{2}$ Agronomia, Universidade Federal do Espírito Santo, Brasil. E-mail: roberto.mauri.marques@gmail.com.

3 Agronomia, Universidade Federal do Espírito Santo, Brasil. E-mail: reinysalves@outlook.com.

${ }^{4}$ Agronomia, Universidade Federal do Espírito Santo, Brasil. E-mail: amandadvargas@hotmail.com.

${ }^{5}$ Agronomia, Universidade Federal do Espírito Santo, Brasil. E-mail: urbano.marialaura@hotmail.com.

${ }^{6}$ Departamento de Produção Vegetal/UFES, Brasil. E-mail: leandropin@yahoo.com.br.
} 